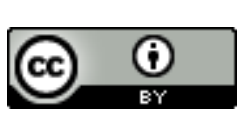

\title{
ENSINO MÉDIO E CONDIÇõES DE TRABALHO DO PROFESSOR EM ESCOLAS PÚBLICAS: CONFIGURAÇõeS E PERSPECTIVAS NAS REGIÕES BRASILEIRAS
}

\begin{tabular}{c}
\hline HIGH SCHOOL AND TEACHER WORKING CONDITIONS IN PUBLIC SCHOOLS: \\
SETTINGS AND PERSPECTIVES IN BRAZILIAN REGIONS \\
\hline ENSEÑANZA SECUNDARIA Y CONDICIONES DE TRABAJO DEL \\
PROFESOR EN LAS ESCUELAS PÚBLICAS: \\
CONFIGURACIÓN Y LAS PERSPECTIVAS EN LAS CINCO REGIONES BRASILEÑAS \\
\hline
\end{tabular}

Gilvan Luiz Machado Costa ${ }^{1}$

\begin{abstract}
RESUMO: O artigo tem como objetivo compreender as configurações e perspectivas para a universalização do acesso e às condições de trabalho do professor no Ensino Médio. A discussão foi realizada com base em indicadores arrolados à qualidade social, com destaque para Taxa de Frequência Líquida e Esforço Docente. A análise explicita disparidades regionais em relação às proposições do Plano Nacional de Educação (2014-2024). Aponta um contexto distante do proposto nas metas 3, 17 e 18 do referido Plano e evidencia desafios em relação para a universalização do acesso e as condições de trabalho do professor nas cinco regiões brasileiras. Sugere que o problema da qualidade social do Ensino Médio não se resolverá com a flexibilização curricular proposta na Lei 13.415/2017. Um caminho alvissareiro seria a universalização do acesso, mormente aos jovens de 15 a 17 anos, e a transformação da docência em uma profissão socialmente atraente. O caminho escolhido pelos mentores da reforma talvez seja o menos promissor.
\end{abstract}

PALAVRAS-ChaVE: Ensino médio. Universalização. Condições de trabalho.

ABSTRACT: The article has as aim to understand the settings and perspectives to the universalization of the access and the working conditions to the teacher in the High School. The discussion was carried out based on indicators regarding to the social quality, Highlighting the Liquid Frequency Rate and Teaching Effort. The analysis makes explicit regional disparities regarding to the proposals of the National Education Plan (20142024). It points a distant context from the goals 3, 15, 17 and 18 of the National Education Plan (2014-2024) and makes evident challenges regarding to the universalization of the access and to the work conditions of the professor in the High School in the five Brazilian regions. It suggests that the social quality issue of the High Scholl will not be solved with the curriculum flexibility proposed by the Law Lei 13.415/2017. A hopeful path would be the universalization to the access, mainly for young people from 15 to 17 years old and changing the teaching into a social attractive profession. The path chosen by the mentors of the reform is perhaps the least promising.

KEYWORDS: High school. Universalization. Work conditions.

RESUMEN: El artículo tiene el objetivo de comprender la configuración y las perspectivas para universalización del acceso y condiciones de trabajo del profesor en la Enseñanza Secundaria. La discusión fue basada en indicadores en relación con la cualidad social, con despegue para la Tasa de Frecuencia Líquida y el Esfuerzo Docente. El análisis explicita disparidades regionales en lo referente a las propuestas del Plan Nacional de Educación (2014-2024). Apunta un contexto lejos del propuesto en las metas 3, 17 y 18 del Plan Nacional de

Submetido em: 18/09/2017 - Aceito em: 17/11/2017 - Publicado em: 23/03/2018

\begin{tabular}{l|c|c|c|c|c|c} 
(C) Rev. Educ. Perspec. & Viçosa, $M G$ & v.9 & n.1 & p.87-103 & jan./abr.2017 & eISSN 2178-8359 \\
\hline
\end{tabular}


Educación (2014-2024), y hace evidente desafíos relacionados con la universalización del acceso y con las condiciones de trabajo del profesor de la Enseñanza Secundaria en las cinco regiones brasileñas. Sugiere que el problema de la cualidad social de la Enseñanza Secundaria no se va a resolver con la flexibilización curricular propuesta por la Ley 13.415/2017. Un camino de esperanza sería la universalización del acceso, principalmente de los jóvenes de 15 a 17 años, y la transformación de la docencia en una profesión socialmente atractiva. El camino elegido por los mentores de la reforma es quizás el menos prometedor.

PALABRAS CLAVE: Enseñanza secundaria. Universalización. Condiciones de trabajo.

\section{INTRODUÇÃO}

A obrigatoriedade e gratuidade da Educação Básica para a faixa etária de 4 a 17 anos está assinalada na Constituição Federal, via Emenda Constitucional n ${ }^{\circ}$ 59/2009. Esta conquista significativa tornaria o Ensino Médio obrigatório para os jovens de 15 a 17 anos, idade adequada para frequentá-lo, "não fossem as desigualdades de acesso à escola, os itinerários descontínuos e as distorções no âmbito do sistema educacional” (SILVA, 2015, p. 370). A centralidade desde a promulgação da Lei nº 9.394 de 1996 (LDB), que atribuiu ao Ensino Médio estatuto de etapa da Educação Básica, foram as tentativas de reformulação do currículo e evidenciam disputas em torno dos sentidos e finalidades do Ensino Médio. Ao mesmo tempo, expressam que outras dimensões foram silenciadas.

Ganha proeminência no tempo presente a sanção da Lei ${ }^{\circ} 13.415 / 2017$, que traz uma proposta de reforma ancorada na flexibilização curricular (KRAWCZYK; FERRETTI, 2017). A referida legislação coloca holofotes mais uma vez sobre o currículo do Ensino Médio e retira, do centro das discussões, a ausência de políticas públicas que promovam sua oferta com qualidade social ${ }^{1}$. A articulação entre as relações sociais mais amplas e as dimensões intraescolares acomodam o conceito de qualidade social do Ensino Médio. O direito ao Ensino Médio de qualidade social constitui um grande desafio para o Estado, quando se considera o Brasil com suas assimetrias regionais e desigualdades sociais (DOURADO, 2013). Mais especificamente, demanda portas abertas para todos, mormente aos jovens de 15 a 17 anos, professores licenciados nas disciplinas que lecionam e com carreira e condições de trabalho condignas, pautadas na formação humana integral ${ }^{2}$.

A partir destas reflexões, este artigo foca a análise nas cinco regiões brasileiras, com ênfase nas dimensões intraescolares, centrais ao Ensino Médio com qualidade social: universalização do acesso e condições de trabalho ${ }^{3}$ dos professores, pautadas nas metas 3,17 e 18 do Plano Nacional de Educação (PNE), aprovado pela Lei n ${ }^{\circ}$ 13.005/2014. Com o intuito de contribuir com a necessária discussão sobre a última etapa da Educação Básica no domínio das mudanças trazidas pela Lei $\mathrm{n}^{\circ} 13.415 / 2017$, problematizou-se: quais as configurações e perspectivas para a universalização do acesso e às condições de trabalho dos professores do Ensino Médio que atuam nas escolas estaduais ${ }^{4}$ nas regiões do Brasil?

\begin{tabular}{l|c|c|c|c|c|c|} 
(C) Rev. Educ. Perspec. & Viçosa, $M G$ & v.9 & n.1 & p.87-103 & jan./abr.2017 & eISSN 2178-8359 \\
\hline
\end{tabular}


Os subsídios empíricos para a referida problematização foram buscados na Pesquisa Nacional por Amostra de Domicílios (PNAD) e no Censo Escolar da Educação Básica, sobretudo na Taxa de Frequência Líquida (TFL) e no indicador educacional Esforço Docente, e nas metas 3,17 e 18 do PNE. Os dados foram cotejados com parte da produção bibliográfica relacionada à temática do estudo. A análise pautou-se nas seguintes categorias de conteúdo: universalização do acesso no Ensino Médio e condições de trabalho do professor.

Utilizaram-se os pressupostos teórico-metodológicos de imersão nos dados quantitativos e qualitativos, com intuito de ir além da compreensão imediata do Ensino Médio. Buscou-se compreender a universalização e as condições de trabalho dos professores do Ensino Médio explicitando dialeticamente suas relações com o contexto econômico, político, social e cultural (NOSELLA; BUFFA, 2005). Na análise, o objeto de estudo foi tomado na relação inseparável entre o plano estrutural e o conjuntural (FRIGOTTO; CIAVATTA, 2011).

\section{UNIVERSALIZAÇÃO DO ACESSO AO ENSINO MÉDIO}

Percursos formativos instáveis aparecem entre os jovens pertencentes ao grupo de idade 15 a 17 anos que estão fora da escola ou retidos no Ensino Fundamental. Uma situação ideal seria aquela em que todos com idade adequada estivessem no Ensino Médio. Neste caso, a Taxa de Frequência Bruta (TFB) e a Taxa de Frequência Líquida (TFL) seriam de 100\%. Vale destacar que o primeiro indicador aponta o percentual de jovens matriculados na Educação Básica, e o segundo expressa o percentual de matriculados no Ensino Médio. A Tabela 1 permite avaliar o acesso da população de 15 a 17 anos ao Ensino Médio nas cinco regiões do Brasil.

Tabela 1. População residente de 15 a 17 anos, matrículas no Ensino Médio e Taxas de Frequência Bruta e Líquida - Regiões Geográficas - 2013/2015

\begin{tabular}{lccccc}
\hline Ano & População & Matrícula & TFB & TFL \\
& Localização & Total & $(\%)$ & $(\%)$ \\
\hline 2013 & Norte & 1061 & 779 & 84,1 & 45,8 \\
2013 & Nordeste & 3231 & 2.312 & 83,1 & 47,6 \\
2013 & Sudeste & 4149 & 3.447 & 85,9 & 65,1 \\
2013 & Sul & 1410 & 1.147 & 83,2 & 62,4 \\
$\mathbf{2 0 1 3}$ & Centro-oeste & 792 & 630 & 83,7 & 59,9 \\
2015 & Norte & 1.089 & 789 & 84,8 & 49,5 \\
2015 & Nordeste & 3.250 & 2.214 & 83,1 & 50,0 \\
2015 & Sudeste & 4.117 & 3.353 & 86,9 & 67,8 \\
2015 & Sul & 1.404 & 1.102 & 84,6 & 61,6 \\
2015 & Centro-oeste & 778 & 618 & 84,4 & 60,7 \\
\hline
\end{tabular}

Fonte: Brasil (2015) e Brasil (2016). 
A região Nordeste, com uma TFB acomodada em 83\%, ano após ano, mantém 552 mil jovens de 15 a 17 anos fora das escolas de Educação Básica. O exame da TFL permite inferir que menos da metade dos jovens de 15 a 17 anos que residem nas regiões Norte e Nordeste não está matriculada no Ensino Médio. Explicita que, somados os que estão fora da escola ou retidos no Ensino Fundamental, atinge aproximadamente 2,1 milhões de jovens residentes nas duas regiões, ausentes do Ensino Médio. Pode-se inferir que as regiões citadas apresentam mais jovens com idade adequada ao Ensino Médio retidos no Ensino Fundamental.

As regiões Sul e Centro-Oeste, com TFL próximas de 60\%; e a Sudeste, com 70\%, apresentam melhor situação. Ao cotejar todas as regiões, os dados revelam que 4,3 milhões de jovens pertencentes ao grupo de idade 15 a 17 anos não estavam matriculados no Ensino Médio. Explicita, nos últimos anos, a persistência em todas as regiões, da ocorrência de aproximadamente 1,5 milhões de jovens de 15 a 17 anos fora da escola, e reiteradamente 2,8 milhões retidos no Ensino Fundamental. Os dados revelam um contingente expressivo de jovens impedidos de se apropriar dos conhecimentos científicos historicamente produzidos, "profunda contradição, diante da presença das ciências e da tecnologia na vida cotidiana" (FRIGOTTO; CIAVATTA, 2011, p. 620).

Ao considerar que o lugar de jovens do grupo de idade 15 a 17 anos é na escola, que frequentem preferencialmente o Ensino Médio e, com base em Saviani (2013), questionam-se os limites e as possibilidades de o Estado brasileiro assumir o dever correlato de garantir a todos esse direito. Esses brasileiros perdem a oportunidade de vivenciar integralmente a adolescência, durante a qual, por meio de experiências orientadas, eles se definem moral, intelectual e socialmente (NOSELLA, 2011). Para o referido autor, os milhões de jovens que não frequentam o Ensino Médio no tempo apropriado não usufruem do momento catártico mais delicado e importante de suas vidas, quando desabrocha o valor da autonomia, que é a liberdade de se posicionar. Com base em Gramsci, Nosella (2011) defende que o Ensino Médio deve ser frequentado e concluído por todos os jovens do grupo de idade 15 a 17 anos, período da vida juvenil em que se consolidam os valores fundamentais do humanismo, a autodisciplina intelectual e a autonomia moral, fundamentais às especializações futuras.

Em todas as regiões brasileiras se observa uma grande dívida com os jovens. Como possibilidade, importa ganhar visibilidade e ser materializada a meta 3 do PNE, que estabelece:

Universalizar, até 2016, o atendimento escolar para toda a população de 15 (quinze) a 17 (dezessete) anos e elevar, até o final do período de vigência deste PNE, a taxa líquida de matrículas no ensino médio para $85 \%$ (oitenta e cinco por cento) (BRASIL, 2014). 
Todas as regiões, em 2015, estavam distantes de universalizar o atendimento escolar para o grupo de idade 15 a 17 anos. Com TFB de 86,9\%, a região Sudeste foi a que se apresentou mais perto da meta $100 \%$. A universalização estava indicada para 2016, mas não se materializou. Em 2016 estavam matriculados, na Educação Básica nas cinco regiões, apenas 8,7 milhões desses jovens (BRASIL, 2016). Tratava-se, e ainda se trata, de um passo necessário em todas as regiões, trazer todos com celeridade para a escola. Resultado semelhante poderá ser verificado com a TFL em 2024.

A reedição de anualmente aproximadamente 1,5 milhões de jovens pertencentes ao grupo de idade 15 a 17 anos não frequentarem nenhuma escola é incompatível com a qualidade social que se quer para a Educação. Destaca-se que a TFB não apresenta discrepância nas cinco regiões. Todas terão o desafio de sair de uma TFB próxima de $85 \%$ para $100 \%$. Ao mesmo tempo, também é imprescindível citar a possibilidade de muitos permanecerem retidos no Ensino Fundamental. Os dados expressam que as regiões Norte e Nordeste, com TFL menor ou igual a 50\%, terão maiores dificuldades para alcançar 85\% em 2024.

De forma contraditória, não se vislumbra, com a Lei $\mathrm{n}^{\circ} 13.415 / 17$, assegurar a todos os brasileiros, residentes de norte a sul, do grupo de idade 15 a 17 anos, o direito do acesso ao Ensino Médio nos próximos anos. A palavra de ordem que se evidencia a partir de 2016, com base no conjunto de mudanças contidas na MP $n^{\circ} 746 / 16$, transformada com algumas alterações na referida Lei, é flexibilização (KRAWCZYK; FERRETI, 2017). A ênfase dos argumentos dos seus propositores é aproximar a "última etapa da educação básica a uma visão mercantil da escola pública e contrariam seu caráter público, inclusivo e universal" (SILVA; SCHEIBE, 2017, p. 28). A universalização não é pauta. A flexibilização curricular proposta não se compromete em "assegurar o direito de cada brasileiro, provendo uma educação com o mesmo padrão de qualidade a toda a população" (SAVIANI, 2013, p. 755).

Por outro lado, o entendimento legal de que o lugar de todos os jovens é na escola implica diminuir a distância entre a Educação Básica, proclamada como direito, e as responsabilidades dos entes federados "de prover os meios para que o referido direito se efetive. Eis porque se impôs o entendimento de que a educação é direito do cidadão e dever do Estado" (SAVIANI, 2013, p. 745). Três décimos da vigência do PNE já se passaram. O primeiro objetivo da meta 3 não foi alcançado e sugere dar, em todas as regiões, com mais intensidade nas regiões Norte e Nordeste, "efetividade à bandeira da escola pública universal, obrigatória, gratuita e laica” (SAVIANI, 2013, p. 745).

Os números do Ensino Médio no Brasil sugerem, por parte do Estado, "elevado investimento; o desenvolvimento de um currículo amplo e articulado de caráter geral; exige professores qualificados e bem pagos, espaço físico adequado" (KUENZER, 2010, p. 864). Evidenciam que as políticas públicas educacionais de acesso e permanência alinhem-se às de valorização

\begin{tabular}{l|c|c|c|c|c|c} 
(C) Rev. Educ. Perspec. & Viçosa, $M G$ & v.9 & n.1 & p.87-103 & jan./abr.2017 & eISSN 2178-8359 \\
\hline
\end{tabular}


dos profissionais da Educação. Tal entendimento encontra-se expresso na Lei $\mathrm{n}^{\circ}$ 13.005/2014 ao trazer, em seu artigo $2^{\circ}$, dentre as diretrizes, a universalização do atendimento escolar; a melhoria da qualidade da educação; e a valorização dos (as) profissionais da educação.

Ampliar a matrícula do Ensino Médio com a elevação da TFL sugere, de acordo com Kuenzer (2011, p. 675), "efetivo investimento em políticas que integrem formação, carreira, remuneração e condições dignas de trabalho". Condições necessárias para enfrentar uma histórica realidade de escassez, inadequação e desprofissionalização do professor, "com seus severos impactos sobre a qualidade do ensino médio, cujas matrículas decrescem a cada ano, assim como não melhoram os indicadores de permanência e de sucesso" (KUENZER, 2011, p. 675).

Vislumbra-se que sejam oferecidas, a todos os jovens, "condições educativas para o aprendizado intelectual, o qual pressupõe denso tempo de leitura, laboratórios, espaço de lazer, arte e cultura" (FRIGOTTO; CIAVATTA, 2011, p. 620). Estas demandas trazem novos desafios aos docentes que, segundo Oliveira (2014, p. 451), “devem também estar em condições de desenvolver a autonomia dos alunos e o seu interesse em seguir aprendendo ao longo da vida". Para enfrentar este desafio, as condições oferecidas aos docentes "não são muitas vezes minimamente adequadas em termos materiais, menos ainda em dimensões subjetivas, que precisam ser cada vez mais observadas" (OLIVEIRA, 2014, p. 451).

Um contexto de mais alunos e mais professores ganha proeminência para as condições de trabalho dos professores, considerada essencial, quando se discute a valorização dos profissionais da Educação (FÓRUM NACIONAL DE EDUCAÇÃO, 2017). Esta dimensão é central na busca da qualidade social do Ensino Médio, e também não foi pautada pelos arautos da reforma.

\section{CONDIÇÕES DE TRABALHO DO PROFESSOR}

No âmbito das condições de trabalho, interessam as relações de emprego, com destaque ao tipo de vínculo, jornada de trabalho, remuneração e formação, vinculados à carreira (PINTO; DUARTE; VIEIRA, 2012). Importa que as políticas educacionais articulem-se em todas as regiões do Brasil para garantir "maior tempo remunerado para os docentes nas escolas, permitindo o desenvolvimento de maiores vínculos com seu trabalho e, logo, maior tempo de dedicação à educação desses jovens" (OLIVEIRA, 2010, p. 275). Tais compreensões são corroboradas por Saviani (2011, p. 16), ao enfatizar que não é possível equacionar devidamente os problemas educacionais sem enfrentar simultaneamente "a questão das condições de exercício do trabalho docente". 
No PNE, aspectos relacionados às condições de trabalho estão diluídos nas diferentes metas e estratégias. A meta $18^{5}$, em sua estratégia 18.1 , destaca a preocupação com o vínculo do professor, ao propor

estruturar as redes públicas de educação básica de modo que, até o início do terceiro ano de vigência deste PNE, noventa por cento, no mínimo, dos respectivos profissionais do magistério [...] sejam ocupantes de cargos de provimento efetivo e estejam em exercício nas redes escolares a que se encontrem vinculados (BRASIL, 2014).

O ingresso do professor do Ensino Médio na carreira docente ainda está muito distante do preconizado na referida estratégia. A tabela 2 demonstra o número de professores efetivos do Ensino Médio da rede estadual de ensino nas regiões brasileiras.

Tabela 2. Professores do Ensino Médio efetivos, dependência administrativa estadual - Regiões 2013/2016

\begin{tabular}{llccc}
\hline Ano & Abrangência & Total & Efetivos & $\%$ \\
\hline 2013 & Norte & 30.838 & 21.980 & 71,3 \\
2013 & Nordeste & 100.337 & 61.267 & 61,1 \\
2013 & Sudeste & 179.187 & 145.058 & 80,1 \\
2013 & Sul & 70.358 & 40.063 & 56,9 \\
2013 & Centro-Oeste & 29.182 & 16.131 & 55,3 \\
2016 & Norte & 31.719 & 23.618 & 74,5 \\
2016 & Nordeste & 102.428 & 64.230 & 62,7 \\
2016 & Sudeste & 179.736 & 131.261 & 73,0 \\
2016 & Sul & 70.466 & 41.275 & 58,6 \\
2016 & Centro-Oeste & 30.679 & 15.825 & 51,6 \\
\hline
\end{tabular}

Fonte: Brasil (2016).

Os dados apontam que, na região Centro-oeste, praticamente $50 \%$ dos professores do Ensino Médio não são concursados, mas possuem contrato, em sua maioria temporário, além do terceirizado ou celetista. As regiões Sul e Nordeste estão próximas dos $40 \%$. Por sua vez, as regiões Norte e Sudeste apresentam números melhores, mas ainda possuem mais de $25 \%$ dos seus professores contratados de forma precária.

Ao apresentar um número expressivo de professores com contratos temporários de forma persistente nas cinco regiões, evidencia-se, com base em Oliveira (2006), certa precarização nos aspectos concernentes às relações de emprego oferecidas. Os contratos temporários são desprovidos de garantias trabalhistas e previdenciárias e, por não assegurarem os mesmos direitos e garantias dos professores efetivos, tornam "cada vez mais agudo o quadro de instabilidade e precariedade do emprego" (OLIVEIRA, 2006, p. 216). Não pertencer ao quadro dos efetivos exclui os professores "da complexidade da dinâmica da escola e das relações no interior da mesma, devido sua transitoriedade, limitam a sua participação e 
envolvimento na construção do projeto educativo da escola" (CAMARGO et al., 2006, p. 260).

Por outro lado, uma carreira estável pode tornar a profissão docente mais atraente, ao possibilitar, segundo Camargo et al. (2006, p. 260), "maior segurança para a realização de seu trabalho, uma vez que não estaria sujeito a demissões ao final de licenças, de contratos ou ao final do ano". Com base nos autores mencionados, infere-se que a estabilidade trabalhista, o ingresso em uma carreira docente definida e a realização de seu trabalho com maior segurança sugerem melhores perspectivas às condições de oferta de um Ensino Médio de qualidade social.

O número expressivo de professores do Ensino Médio público estadual em todas as regiões, com contratos temporários, pode ser explicado pela dimensão econômica. Há estreita vinculação entre a forma de contratação e a remuneração dos profissionais da Educação. Os professores temporários têm menores remunerações. Em todas as regiões do Brasil, não se remunera adequadamente os professores efetivos, menos ainda os temporários (OLIVEIRA, 2006).

Valorizar os professores do Ensino Médio seria a opção política natural de um Estado (União, Estados da Federação e Distrito Federal) realmente comprometido com a qualidade social desta etapa da Educação Básica (KUENZER, 2010). Ao considerar os 414.865 professores que lecionam nas escolas estaduais nas cinco regiões brasileiras (BRASIL, 2016a), espera-se que sejam efetivos e possuam condições de trabalho adequadas, como sugere a Lei $\mathrm{n}^{\mathbf{o}}$ 11.738/08 (BRASIL, 2008), que instituiu o Piso Salarial Profissional Nacional (PSPN) para os profissionais do magistério público da Educação Básica com formação em nível médio, na modalidade Normal, para jornada de, no máximo, 40 (quarenta) horas semanais. Na composição da jornada de trabalho, destaca-se o limite máximo de 2/3 (dois terços) da carga horária para o desempenho das atividades de interação com os educandos.

Não obstante, levantamento realizado em 2016 pela Confederação Nacional dos Trabalhadores em Educação (CNTE) explicita que a referida lei não é cumprida nos quesitos Piso e Jornada Extraclasse de norte a sul por seis dos estados da federação: Amazonas, Goiás, Maranhão, Paraíba, Rio Grande do Sul e São Paulo. Destaca-se, também, que a aplicação da Lei do Piso tem registrado prejuízos às carreiras do magistério, ofendendo, assim, o dispositivo constitucional (art. 206, V), que preconiza a valorização dos profissionais da Educação por meio de planos de carreira que atraiam e mantenham os trabalhadores nas escolas públicas, contribuindo para a melhoria da qualidade da educação (CNTE, 2016). O cumprimento da Lei $\mathrm{n}^{\mathrm{o}} 11.738 / 08$ remete à meta 17, que propõe "valorizar os (as) profissionais do magistério das redes públicas de educação básica de forma a equiparar seu

\begin{tabular}{l|c|c|c|c|c|c} 
(C) Rev. Educ. Perspec. & Viçosa, $M G$ & v.9 & n.1 & p.87-103 & jan./abr.2017 & eISSN 2178-8359 \\
\hline
\end{tabular}


rendimento médio ao dos (as) demais profissionais com escolaridade equivalente, até o final do sexto ano de vigência deste PNE" (BRASIL, 2014).

Para Masson (2016, p. 161), “a equiparação salarial do professor com as demais profissões é condição indispensável para a atratividade e permanência na carreira, pois é a questão que mais determina a escolha dos jovens, embora isso não seja suficiente". A autora destaca que a remuneração dos professores tem melhorado com a aprovação do PSPN. Por outro lado, aponta que muitos estados da federação têm considerado o valor mínimo como se fosse o máximo.

A valorização dos professores sugere a construção de um Sistema Nacional de Educação (SNE), com ampla colaboração dos estados da federação para usar da prerrogativa de sua autonomia para valorizar seus professores. Importa que os entes federados de todas as regiões do Brasil, de forma articulada e em regime de colaboração, possam consolidar condições objetivas que oportunizem sua implementação (GOUVEIA; PINTO; CORBUCCI, 2011). Condição necessária para superar este contexto adverso de rotatividade de professores, multiplicidade de vínculos empregatícios, e a decorrente extensão da jornada de trabalho docente, opondo-se à qualidade social do Ensino Médio brasileiro (KUENZER, 2010).

Ao mesmo tempo, a valorização salarial com a garantia de satisfação das necessidades básicas, a partir de seu salário mensal recebido da rede de ensino a que está vinculado, pode permitir, por exemplo, que os professores do Ensino Médio dediquem-se a uma determinada escola, e com tempo disponível para elaborar suas aulas. Para Saviani (2011, p. 16), a qualidade do trabalho pedagógico eleva-se com "jornada de trabalho de tempo integral em uma única escola com tempo para aulas, preparação de aulas, orientação de estudos dos alunos, participação na gestão da escola e reuniões de colegiados e atendimento à comunidade".

Neste âmbito, o Instituto Nacional de Estudos e Pesquisas Educacionais Anísio Teixeira (INEP) constrói o indicador Esforço Docente, que mensura o esforço empreendido pelos docentes da Educação Básica brasileira no exercício de sua profissão (BRASIL, 2016a). Considera o número de turnos de trabalho, escolas e etapas de atuação, além da quantidade de alunos atendidos na Educação Básica, e articula-se à jornada de trabalho. O quadro 2 apresenta a descrição dos níveis baseada na distribuição empírica das variáveis.

Quadro 2. Níveis de Esforço Docente

\begin{tabular}{|l|l|}
\hline Nível & Descrição \\
\hline 01 & Docente que tem até 25 alunos e atua em um único turno, escola e etapa. \\
\hline 02 & Docente que tem entre 25 e 150 alunos e atua em um único turno, escola e etapa. \\
\hline 03 & Docente que tem entre 25 e 300 alunos e atua em um ou dois turnos em uma única \\
\hline
\end{tabular}

\begin{tabular}{|l|l|l|l|l|l|l} 
(C) Rev. Educ. Perspec. & Viçosa, $M G$ & v.9 & n.1 & p.87-103 & jan./abr.2017 & eISSN 2178-8359 \\
\hline
\end{tabular}




\begin{tabular}{|l|l|}
\hline & escola e etapa. \\
\hline 04 & $\begin{array}{l}\text { Docente que tem entre } 50 \text { e } 400 \text { alunos e atua em dois turnos, em uma ou duas escolas } \\
\text { e em duas etapas. }\end{array}$ \\
\hline 05 & $\begin{array}{l}\text { Docente que tem mais de } 300 \text { alunos e atua nos três turnos, em duas ou três escolas e } \\
\text { em duas etapas ou três etapas. }\end{array}$ \\
\hline 06 & $\begin{array}{l}\text { Docente que tem mais de } 400 \text { alunos e atua nos três turnos, em duas ou três escolas e } \\
\text { em duas etapas ou três etapas. }\end{array}$ \\
\hline
\end{tabular}

Fonte: Brasil (2016a).

doi: 10.22294/eduper/ppge/ufv.v9i1.908

Não obstante à tentativa de abarcar as duas últimas etapas da Educação Básica, considera-se que o indicador Esforço Docente apresenta limites para a compreensão do Ensino Médio. Qual nível poderia ser a métrica utilizada para acompanhar as estratégias do PNE relacionadas aos aspectos das condições de trabalho do Ensino Médio? Os níveis 05 e 06 expressam claramente a intensificação do trabalho docente ${ }^{6}$. Os dados apresentados na tabela 3 mostram o esforço docente nas escolas estaduais do Ensino Médio em todas as regiões brasileiras.

Tabela 3. Percentual de docentes que atuam no Ensino Médio por níveis do indicador de esforço docente, segundo localização e dependência administrativa Estadual - Brasil - 2013/2016

\begin{tabular}{lcrrrrrc}
\hline Ano & Região & Nível 1 & Nível 2 & Nível 3 & Nível 4 & Nível 5 & Nível 6 \\
\hline 2013 & Norte & 1,7 & 5,2 & 20,7 & 40,8 & 18,6 & 13,0 \\
2013 & Nordeste & 0,8 & 7,8 & 27,5 & 39,4 & 15,6 & 8,9 \\
2013 & Sudeste & 0,5 & 7,3 & 20,4 & 47,1 & 16,5 & 8,2 \\
2013 & Sul & 0,7 & 6,7 & 15,6 & 49,9 & 20,1 & 7,0 \\
2013 & Centro-Oeste & 0,5 & 5,7 & 26,4 & 43,6 & 17,0 & 6,8 \\
2016 & Norte & 2,0 & 5,1 & 20,4 & 43,1 & 17,6 & 11,8 \\
2016 & Nordeste & 1,1 & 7,9 & 26,8 & 40,2 & 15,3 & 8,7 \\
2016 & Sudeste & 0,6 & 7,7 & 20,1 & 47,3 & 16,4 & 7,9 \\
2016 & Sul & 1,0 & 6,4 & 14,9 & 51,0 & 19,6 & 7,1 \\
2016 & Centro-Oeste & 0,7 & 5,8 & 27,8 & 44,1 & 15,1 & 6,5 \\
\hline
\end{tabular}

Fonte: Brasil (2016a).

Ressalta-se que, na região Norte, no interregno 2013 a 2016, aproximadamente 30\% dos professores do Ensino Médio das escolas estaduais concentraram-se nos níveis 05 e 06. Próximas de $25 \%$ aparecem as regiões Nordeste, Sudeste e Sul. Com números melhores, mas igualmente preocupantes, está a região Centro-Oeste. Os dados revelam uma jornada extensa e intensa em todas as regiões. Trabalhar em mais de uma escola, em três turnos e com muitos alunos de diferentes etapas da Educação Básica faz parte do cotidiano de uma parcela expressiva dos professores da última etapa da Educação Básica, que lecionam nas escolas estaduais. Os dados explicitam a persistência da grande concentração de professores, mormente na região Norte, com mais de 300 alunos e atuando nos três turnos, em duas ou três escolas e em duas ou três etapas. Constata-se que o esforço docente é alto no cotidiano de 
uma parcela expressiva dos professores da última etapa da Educação Básica, do Oiapoque ao Chuí.

A dedicação a uma escola e de jornadas não exaustivas parece não ser uma realidade dos professores do Ensino Médio. Por outro lado, sua conquista resulta, segundo Camargo et al. (2006, p. 273), "numa satisfação que, além de promover condições para uma oferta de ensino de qualidade, evita prejuízos à saúde do trabalhador e permite tempo para aqueles interessados em processos complementares de qualificação profissional”. Como contraponto a uma jornada de trabalho extensa e intensa, com muitas escolas, turnos, alunos e etapas, variáveis que compõem o indicador Esforço Docente, destaca-se a estratégia 17.3 contida no PNE, que incorpora as conquistas da Lei $\mathrm{n}^{\circ} 11.738$ :

\begin{abstract}
implementar, no âmbito da União, dos Estados, do Distrito Federal e dos Municípios, planos de Carreira para os (as) profissionais do magistério das redes públicas de educação básica, observados os critérios estabelecidos na Lei $\mathrm{n}^{\circ}$ 11.738 , de 16 de julho de 2008, com implantação gradual do cumprimento da jornada de trabalho em um único estabelecimento escolar (BRASIL, 2014).
\end{abstract}

A materialização do proposto nas metas do PNE poderá representar maior valorização social do professor (MASSON, 2016). Considera-se, ainda, a complexidade do currículo do Ensino Médio com treze componentes curriculares distribuídos em vinte e cinto aulas semanais, e os limites de um professor cumprir sua carga horária em um único estabelecimento. Todavia, com base em Camargo et al. (2016), a construção da possibilidade de os professores das escolas estaduais do Ensino Médio se dedicarem a somente uma escola está vinculada a todas as dimensões da valorização dos profissionais da Educação, em outras palavras, articula-se com a formação, a carreira, a remuneração e as condições de trabalho.

A discussão sobre aspectos das condições de trabalho alinha-se à qualidade social do Ensino Médio. Alves e Pinto (2011, p. 633) lembram que a conquista de uma escola pública de qualidade para todos passa por uma adequada jornada de trabalho, que contemple "hora de trabalho extraclasse a ser cumprida na escola e estimule a dedicação exclusiva à docência e, preferencialmente, em uma única escola". A este componente, os autores incorporam a remuneração adequada. Para os autores, equacionados esses dois componentes, "as condições necessárias, embora não suficientes, para um salto de qualidade na educação básica estarão dadas" (ALVES; PINTO, 2011, p. 633).

No âmbito do Ensino Médio, os indicadores visitados mostraram que a qualidade social está para ser conquistada em todas as regiões brasileiras. Ao mesmo tempo, como possiblidades, na perspectiva da qualidade social do Ensino Médio (KUENZER, 2010), sem desconsiderar suas vicissitudes, enfatiza-se o PNE, que aponta, nas metas que tratam da universalização do acesso e da valorização dos profissionais da Educação, perspectivas virtuosas também para a última etapa da Educação Básica.

\begin{tabular}{l|l|l|l|l|l|l} 
(ㄱ) Rev. Educ. Perspec. & Viçosa, $M G$ & v.9 & n.1 & p.87-103 & jan./abr.2017 & eISSN 2178-8359 \\
\hline
\end{tabular}


As mudanças no Ensino Médio não podem ignorar "que as escolas não possuem as condições básicas de funcionamento institucional nem do exercício do trabalho dos professores, oferecendo aos estudantes condições dignas de aprendizagem" (KRAWCZYK; FERRETTI, 2017, p. 38). A reforma contida na Lei n. 13.415/2017 silencia, em aspectos absolutamente indispensáveis, a qualidade social do Ensino Médio, que reivindica uma formação integral. Como acento, a proposta de flexibilização curricular não oferece um caminho na direção da referida formação. Ignora que sua conquista de norte a sul suscita um Ensino Médio para todos, e um "contexto em que o prestígio social dos professores estão consolidados" (MORAES, 2017, p. 424).

\section{CONSIDERAÇÕES}

Neste artigo procurou-se problematizar as categorias de conteúdo universalização do acesso e condições de trabalho do professor no Ensino Médio nas escolas estaduais, e os desafios à materialização das metas 3, 17 e 18 do PNE.

No âmbito da universalização do acesso, há um problema quantitativo a ser superado: reiteradamente, aproximadamente 4,3 milhões de jovens de 15 a 17 anos não frequentam o Ensino Médio. A qualidade social não será alcançada sem a efetivação do atendimento escolar para todos da faixa etária 15 a 17 anos. Proposta em Lei para 2016, a universalização ainda não se materializou em nenhuma das regiões, e importa que seja priorizada. Os dados expressam que as regiões Norte e Nordeste, com TFL menor ou igual a 50\%, terão maiores dificuldades para alcançar os $85 \%$ propostos no PNE para 2024. A persistência, a cada ano, de aproximadamente 1,5 milhões de jovens pertencentes ao grupo de idade 15 a 17 anos fora da escola, e 2,8 milhões retidos no Ensino Fundamental não condiz com a conquista de uma Educação de qualidade social no Brasil, que se quer republicana, pública, gratuita e para todas e todos. Reitera-se que, entre os 4,3 milhões de jovens, aproximadamente 2,1 milhões residem nas regiões Norte e, maiormente, Nordeste.

Com relação às condições de trabalho, ao considerar o contingente de 414.865 professores, os indicadores educacionais visitados revelam entraves e desafios relacionados à valorização dos profissionais que lecionam no Ensino Médio em escolas estaduais nas regiões brasileiras. Os dados apontam que a região Centro-Oeste apresenta praticamente a metade de seus professores do Ensino Médio como não concursados. Próximos da Região Centro-Oeste estão as regiões Sul e Nordeste. As regiões Norte e Sudeste apresentam números melhores, mas ainda conta com mais de $25 \%$ dos seus professores contratados de forma precária. Os dados também mostram, em todas as regiões, redes estaduais de ensino que sequer cumprem a Lei $\mathrm{n}^{\mathrm{o}} 11.738 / 2008$ nos quesitos vencimento básico e carga horária.

\begin{tabular}{|c|c|c|c|c|c|c} 
(C) Rev. Educ. Perspec. & Viçosa, $M G$ & v.9 & n.1 & p.87-103 & jan./abr.2017 & eISSN 2178-8359 \\
\hline
\end{tabular}


Realça-se que, de norte a sul, o Ensino Médio convive com professores que trabalham em muitas escolas, com muitos alunos, etapas e turnos. Mesmo com os limites do indicador Esforço Docente, os dados indicam, nas cinco regiões, um percentual expressivo de professores das escolas estaduais com mais de 300 alunos, que atuam nos três turnos, em duas ou três escolas e em duas ou três etapas. No entanto, também evidenciam desigualdades regionais. A região Norte apresentou aproximadamente $30 \%$ dos professores do Ensino Médio das escolas estaduais concentrados nos níveis 05 e 06. Próximas de $25 \%$ aparecem as regiões Nordeste, Sudeste e Sul. Com números melhores, mas igualmente preocupantes, está a região Centro-Oeste. Os dados evidenciam uma jornada extensa e intensa em todas as regiões.

O Brasil tem uma grande dívida com os jovens e com os profissionais da Educação. A dimensão universalização do acesso é mais reivindicada nas regiões Norte e Nordeste. Por sua vez, condições de trabalho mostrou maior apelo nas regiões Centro-Oeste, Norte e Sul. Sem desconsiderar as desigualdades regionais, o compromisso e a concretização das metas 3 , 17 e 18 do PNE mostram-se fundamentais de norte a sul.

A qualidade social do Ensino Médio só será materializada com todos os jovens na escola, frequentando o Ensino Médio, e a efetiva valorização dos profissionais da Educação, consubstanciada na formação, remuneração, carreira e condições de trabalho adequadas. Somente com todos os professores valorizados e prestigiados, e com sólida formação teórica, pode-se vislumbrar a garantia, a todos os jovens brasileiros, do direito social à conclusão do Ensino Médio em todas as regiões do Brasil.

Também se considera igualmente fundamental a institucionalização de um SNE e da aplicação de $10 \%$ do Produto Interno Bruto (PIB) em educação pública, previstos no PNE. A materialização da qualidade social do Ensino Médio sugere mais recursos financeiros para a Educação, e não o contrário. A gestão e o financiamento da Educação, no âmbito do estabelecido na Lei $\mathrm{n}^{\circ}$ 13.005/2014, constituem-se em elementos articuladores de um esforço coletivo dos entes federados na materialização das metas do PNE, com destaque àquelas relacionadas com a universalização do acesso e à valorização do professor do Ensino Médio das escolas estaduais.

O problema da qualidade social do Ensino Médio, colocado com muita intensidade no centro das discussões com a sanção da Lei ${ }^{\circ} 13.415 / 2017$, não se resolverá com a flexibilização da proposta curricular. Mudar o Ensino para melhor se faz necessário na busca da qualidade social. Um caminho alvissareiro em todas as regiões seria a universalização do acesso, mormente aos jovens de 15 a 17 anos, e a transformação da docência em uma profissão socialmente atraente. $\mathrm{O}$ caminho escolhido pelos mentores da reforma talvez seja o menos promissor.

\begin{tabular}{l|c|c|c|c|c|c} 
() Rev. Educ. Perspec. & Viçosa, $M G$ & v.9 & n.1 & p.87-103 & jan./abr.2017 & eISSN 2178-8359 \\
\hline
\end{tabular}




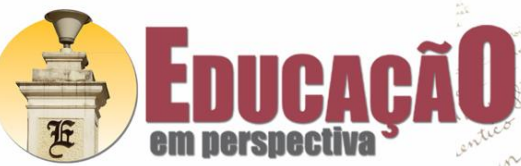

\section{REFERÊNCIAS}

ALVES, Thiago; PINTO, José Marcelino de Rezende. Remuneração e características do trabalho docente no Brasil: um aporte. Cadernos de Pesquisa, São Paulo, v. 41, p. 606-639, 2011.

BRASIL. Lei de Diretrizes e Bases da Educação Nacional. Lei nº 9.394 de 20 de dezembro de 1996.

BRASIL. Lei n⿳ 11.738, de 16 de julho de 2008. Regulamenta a alínea "e" do inciso III do caput do art. 60 do Ato das Disposições Constitucionais Transitórias, para instituir o piso salarial profissional nacional para os profissionais do magistério público da educação básica. Brasília, 2008.

BRASIL. Lei n⿳ 13.005, de 25 de junho de 2014. Aprova o Plano Nacional de Educação PNE e dá outras providências. Diário Oficial da União, Brasília, DF, 2014.

BRASIL. Pesquisa Nacional por Amostra de Domicílios (PNAD): 1991-2015. Brasília, 2015.

BRASIL. Censo Escolar da Educação Básica, 1995 a 2016. Ministério da Educação. Instituto Nacional de Estudos e Pesquisas Educacionais. Brasília: MEC/INEP, 2016.

BRASIL. Indicador de Esforço Docente. Instituto Nacional de Estudos e Pesquisas Educacionais Anísio Teixeira Diretoria de Estatísticas Educacionais. Nota Técnica ${ }^{\circ}$ 039/2014. Brasília, 2016a.

BRASIL. Lei no 13.415 de 16 de fevereiro de 2017. Institui a Política de Fomento à Implementação de Escolas de Ensino Médio em Tempo Integral. Brasília, DF, 2017.

CAMARGO, Rubens Barbosa; GOUVEIA, Andréa Barbosa; CRUZ, Rosana Evangelista da; OLIVEIRA, João Ferreira de. Condições de trabalho docente, ensino de qualidade e custoaluno-ano. Revista Brasileira de Política e Administração da Educação, Goiânia, v. 22, p. 253-276, 2006.

CONFEDERAÇÃO NACIONAL DOS TRABALHADORES EM EDUCAÇÃO - CNTE. Tabela de Vencimentos. Brasília, 2016.

DOURADO, Luiz Fernandes. Sistema Nacional de Educação, Federalismo e os obstáculos ao direito à Educação Básica. Educação e Sociedade, Campinas, v. 34, n. 124, p. 761-785, jul./set. 2013.

FÓRUM NACIONAL DE EDUCAÇÃO. CONAE 2018: Conferência Nacional de Educação: documento - referência. Fórum Nacional de Educação. Brasília, 2017.

\begin{tabular}{|l|l|l|l|l|l|l} 
(C) Rev. Educ. Perspec. & Viçosa, $M G$ & v.9 & n.1 & p.87-103 & jan./abr.2017 & eISSN 2178-8359 \\
\hline
\end{tabular}


FRIGOTTO, Gaudêncio; CIAVATTA, Maria. Perspectivas sociais e políticas da formação de nível Médio: avanços e entraves nas suas modalidades. Educação e Sociedade, Campinas, v. 32, n. 116, p. 619-638, jul./set. 2011.

GOUVEIA, Andréa Barbosa; PINTO, José Marcelino de Rezende; CORBUCCI, Paulo Roberto (Orgs.). Federalismo e políticas educacionais na efetivação do direito à educação. Brasília: IPEA, v. 1, 2011. 227 p.

KRAWCZYK, Nora; FERRETTI, Celso João. Flexibilizar para quê? Meias verdades da "reforma". Revista Retratos da Escola, Brasília, v. 11, n. 20, p. 33-44, jan./jun. 2017.

KUENZER, Acácia Zeneida. O Ensino Médio no plano nacional de educação 2011-2020: superando a década perdida? Educação e Sociedade, Campinas, v. 31, n. 112, p. 851-873, jul./set. 2010.

KUENZER, Acácia Zeneida. A formação de professores para o Ensino Médio: velhos problemas, novos desafios. Educação e Sociedade. Campinas, v. 32, n. 116, p. 667-688, jul./set. 2011.

MASSON, Gisele. A valorização dos professores e a educação básica nos estados. Revista Retratos da Escola, Brasília, v. 10, p. 157-174, 2016.

MORAES, Carmen Sylvia Vidigal. O ensino médio e as comparações internacionais: Brasil, Inglaterra e Finlândia. Educação e Sociedade, Campinas, v. 38, n. 139, p. 405-429, abr./set. 2017.

NOSELLA, Paolo. Ensino Médio: em busca do princípio pedagógico. Educação e Sociedade, Campinas, v. 32, n. 117, p. 1051-1066, out./dez. 2011.

NOSELLA, Paolo; BUFFA, Ester. As pesquisas sobre Instituições Escolares: o método dialético marxista de investigação. Eccos Revista Científica, São Paulo, v. 7, n. 2, p. 351368, jul./dez. 2005.

OLIVEIRA, Dalila Andrade. Regulação Educativa na América Latina: repercussões sobre a identidade dos trabalhadores docentes. Educação em Revista (UFMG), v. 44, p. 209-227, 2006.

OLIVEIRA, Dalila Andrade. O Ensino Médio perante a obrigatoriedade ampliada: que lições podemos tirar de experiências observadas? Revista Brasileira de Estudos Pedagógicos, Brasília, v. 91, p. 10-26, 2010.

OLIVEIRA, Dalila Andrade. Os docentes no Plano Nacional de Educação: entre a valorização e a desprofissionalização. Revista Retratos da Escola, Brasília, v. 8, n. 15, p. 447-461, jul./dez. 2014. 
OLIVEIRA, Dalila Andrade. Carreira e piso nacional salarial para profissionais da educação básica. Revista Retratos da Escola, Brasília, v. 10, p. 121-140, 2016.

OLIVEIRA, Dalila Andrade; ASSUNÇÃO, Ada Avila . Condições de trabalho docente. Belo Horizonte: GESTRADO/FAE/UFMG, 2010 (Verbete).

PINTO, Mércia Noronha; DUARTE, Adriana; VIEIRA, Livia Maria Fraga. O trabalho docente na educação infantil pública de Belo Horizonte. Revista Brasileira de Educação, v. 17, p. 611-626, 2012.

SAVIANI, Dermeval. Vicissitudes e perspectivas do direito à educação no Brasil: abordagem histórica e situação atual. Educação e Sociedade, Campinas, v. 34, n. 124, p. 743- 760, jul./set. 2013.

SAVIANI, Dermeval. Formação de professores no Brasil: dilemas e perspectivas. Poíesis Pedagógica, v. 9, n. 1, jan./jun. 2011.

SILVA, Monica Ribeiro da. Direito à educação, universalização e qualidade: cenários da Educação Básica e da particularidade do Ensino Médio. Jornal de Políticas Educacionais, v. 9, p. 61-74, 2015.

SILVA, Monica Ribeiro da; SCHEIBE, Leda. Reforma do ensino médio: Pragmatismo e lógica mercantil. Revista Retratos da Escola, Brasília, v. 11, n. 20, p. 19-31, jan./jun. 2017.

\section{NOTAS}

${ }^{1} \mathrm{O}$ conceito de qualidade social conforma a articulação entre as dimensões extraescolares e intraescolares. "As primeiras dizem respeito às condições socioeconômicas e culturais, dos direitos e das obrigações e garantias. As segundas referem-se a condições: a) de oferta, de gestão e organização do trabalho nas instituições educativas; b) de valorização, formação, profissionalização e ação pedagógica; c) de acesso, permanência e desempenho escolar e acadêmico" (FÓRUM NACIONAL DE EDUCAÇÃO, 2017, p. 19).

${ }^{2}$ Formação que permita, ao jovem, "entender ampla e criticamente tanto a sociedade em que vivem quanto a forma pela qual se estrutura o trabalho que realizam, tendo em vista a construção de formas mais humanas e igualitárias de produzir e viver" (KRAWCZYK; FERRETTI, 2017, p. 40).

${ }^{3}$ Com base em Oliveira e Assunção (2010), a noção de condições de trabalho designa o conjunto de recursos que possibilitam a realização do trabalho do professor, envolvendo as instalações físicas, os materiais e insumos disponíveis, os equipamentos e meios de realização das atividades pedagógicas. Envolvem, também, no âmbito das relações de emprego, elementos concernentes à carreira docente, com destaque ao vínculo, à remuneração e à jornada de trabalho.

${ }^{4} \mathrm{O}$ foco deste trabalho é analisar aspectos do acesso e da valorização dos professores das escolas estaduais. A dependência administrativa estadual detém aproximadamente $85 \%$ da matrícula nesta etapa da Educação Básica.

5 “Assegurar, no prazo de dois anos, a existência de planos de carreira para os (as) profissionais da educação básica e superior pública de todos os sistemas de ensino e, para o plano de carreira dos (as) profissionais da educação básica pública, tomar como referência o piso salarial nacional profissional, definido em lei federal, nos termos do inciso VIII do art. 206 da Constituição Federal” (BRASIL, 2014).

\begin{tabular}{l|c|c|c|c|c|c} 
(C) Rev. Educ. Perspec. & Viçosa, $M G$ & v.9 & n.1 & p.87-103 & jan./abr.2017 & eISSN 2178-8359 \\
\hline
\end{tabular}


${ }^{6}$ Para Oliveira (2006), a intensificação do trabalho docente resulta da ampliação da jornada de trabalho e do aumento considerável de responsabilidades que os docentes tiveram com as reformas mais recentes. Com base na autora, a intensificação do trabalho docente pode ser intensa, com a ampliação das funções/tarefas; e/ou extensa, com a ampliação da jornada de trabalho.

\section{SOBRE O AUTOR}

${ }^{1}$ Gilvan Luiz Machado Costa: Doutorado em Educação pela Universidade Estadual de Campinas. Professor do Programa de Pós-graduação da Universidade do Sul de Santa Catarina. E-mail: gilvan.costa@unisul.br 